\title{
The war on want
}

\author{
Many 'developing' countries are much more developed than some people think. Their rapid progress \\ should inspire scientists and their institutions to do more to confront global poverty.
}

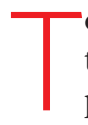
o those living in comfort in the affluent parts of the world, the stark reality behind the word poverty is difficult to comprehend. Yet it is more incomprehensible that in the twentyfirst century, hundreds of millions of people are so poor that their lives amount to little more than a daily struggle to survive. Faced by such desperate circumstances, the affluent often succumb to an overwhelming sense of impotence. But defeatism would be a mistake: the battle against poverty can be won, and science can help.

Looking at the powerhouse of medical research that is the US National Institutes of Health (NIH), it is difficult to imagine that it began life 120 years ago in a small attic room in the Marine Hospital Service on Staten Island, New York. Joseph Kinyoun's one-man 'laboratory of hygiene', the first federal disease lab, was created to identify the causes of several infectious diseases that at the time were responsible for high mortality in the United States. The rest is history.

That concept of time is vital to understanding poverty. In 1915, the United States resembled India today on several poverty indicators, from child mortality to life expectancy, and Mexico has now achieved standards of human development equivalent on some scores to Sweden in the 1950s. Many of the countries labelled as 'Third World' are in fact well along the same trajectory to prosperity as today's wealthy nations. Yet growing prosperity means that new technologies are needed even more urgently, because as more countries escape the shackles of poverty, demand for energy, water and other resources will exacerbate the problems, such as climate change, that face our planet.

\section{Exploded myths}

It is essential that the myths about poverty are debunked for policymakers. Few scientists have done more in this regard than Hans Rosling, a global-health researcher at the Karolinska Institute in Stockholm. Extracting and collating vast amounts of data on poverty, he has created stunning visualizations that vividly dispel many preconceived ideas about poverty (see http://tinyurl.com/34bsyr). He also highlights the importance of factors such as good governance and institutional capacity building, showing, for instance, that although economic growth is the motor of escape from poverty, that escape is achieved faster when public health is improved.

This is an example of how science can help to frame the problems properly. Aid agencies must similarly pay more attention to evaluating the effectiveness of resource allocations and interventions. Too often in the past, advocacy of policies has been based on the latest economic theory in fashion, rather than on hard evidence. Better data on poverty indicators, in particular at the subnational level, are also needed if we are to assess the true effects of the interventions designed to meet the UN Millennium Development Goals of halving poverty by 2015 (see Nature 446, 347; 2007).

In one welcome initiative, the World Bank has embraced an innovative approach to evaluation. Pioneered at the Massachusetts
Institute of Technology in Cambridge, it borrows the techniques of randomized trials used in medicine to assess the impact of health and education initiatives, such as bed nets for malaria, and the factors that affect their success (see page 957).

But fighting poverty more effectively demands a change of culture not only in aid agencies but also in academia, in particular to bridge the gap between basic
"Leaders of academic institutions should be asking themselves how their organizations can do more to combat poverty." research and the development of drugs and vaccines for neglected diseases. The scientific community's reward structures, excessively focused on papers and patents, need to encourage efforts to use science to generate tangible benefits - not least in alleviating poverty and its impacts.

\section{Measured response}

Only a few universities have, for example, created centres for biomedical translational research, evaluated not by the usual metrics but by their results, much as a company assesses project performance. Far more could be done along these lines in agriculture, energy and health.

That said, there are encouraging signs that decades of focus on wealth creation are slowly giving way to a greater social conscience. Technology-transfer offices at the NIH and many universities, for example, are increasingly waking up to the importance of making their patents freely available to groups developing technologies for use in poor countries (see Nature 449, 158-159; 2007).

At a time when many sectors of society are actively engaged in working towards the Millennium Development Goals, the leaders of academic institutions should be asking themselves how their organizations can do more to combat poverty and improve global health. The eight goals themselves are ambitious to say the least. It will be a tall order to halve extreme poverty, roll back child mortality and provide universal primary education, all by 2015 .

But many previously impoverished countries are now well on their way to enjoying levels of child mortality, longevity and health comparable to those of the richest countries. That should encourage scientists to help speed up the progress of those nations that still have far to go - and to strengthen their scientific infrastructure. The gleaming, state-of-the art Manhiça Health Research Center near Maputo in Mozambique, for example, may seem incongruous with the immediate disease and misery on its doorstep. Yet in a few decades it may be remembered as that nation's Staten Island lab.

This article is part of the Global Theme on Poverty and Human Development, organized by the Council of Science Editors. All articles from the Nature Publishing Group are available free at www.nature.com/povhumdev. The content from all participating journals can be found at www.councilscienceeditors.org/ globalthemeissue.cfm. 